\title{
Power Quality Improvement in Solar-Wind based Power System using BESS
}

\author{
Rajesh Kumar \\ M.Tech Scholar, Electrical Engineering Department \\ RPIIT, Karnal, India
}

\author{
Satish Kumar \\ Professor, Electrical engineering Department \\ RPIIT, Karnal, India
}

\section{ABSTRACT}

As solar photovoltaic and wind based power generation becomes more commonplace, the inherent intermittency of the solar and wind resource poses one of the great challenges to those who would design and implement the next generation smart grid. Specifically, grid-tied solar power generation is a distributed resource whose output can change extremely rapidly, resulting in many issues for the distribution system operator with a large quantity of installed photovoltaic devices. Battery energy storage systems are increasingly being used to help integrate solar and wind power into the grid. These systems are capable of absorbing and delivering both real and reactive power with sub-second response times. With these capabilities, battery energy storage systems can mitigate such issues with solar-wind power generation as ramp rate, frequency, and voltage issues. Beyond these applications focusing on system stability, energy storage control systems can also be integrated with energy markets to make the solar and wind resource more economical. Providing a high-level introduction to this application area, this paper presents an overview of the challenges of integrating solar and wind power to the electricity distribution system.

In this paper a solar-wind based power system model is made. To smoothen the intermittency of the solar and wind resources a battery energy storage system (BESS) is employed. The battery energy storage system stores the energy when excess power is available and releases the stored energy when demand is higher than the supply. A PI controller based control scheme is implemented for this purpose and an MPPT is used for wind turbine to extract the maximum power from the wind resource.

The validity of the control scheme is checked through the MATLAB simulation of the solar-wind based power system.
KEYWORDS: Battery energy storage systems, photovoltaic, renewables, solar, proportional integral regulator, power quality.

\section{INTRODUCTION}

This Alternative energy sources such as solar and wind energies, has attracted many researchers and communities throughout the world since the "energy crisis" of the 1970s. In addition, the increasing energy demand, high energy prices, as well as increasing concerns over environmental-, health- and climate changed implications of energy related activities are increasing concerns on alternative energy studies in communities [1-2].

The high costs of electricity may be due to centralized energy systems which operate mostly on fossil fuels and require large investments for establishing transmission and distribution grids that can penetrate remote regions [3]. Furthermore, the fossil fuel combustion results in the emission of obnoxious gases rising concerns about the climate change and other health hazards.

In order to counter these problems there is a strong need for alternative systems of power generation and distribution. Unlike the centralized energy systems, on the other hand, decentralized energy systems are mostly based on renewable energy sources. They operate at lower scales (a few $\mathrm{kWh}$ scale) both in the presence and absence of grid, and easily accessible to remote locations because of generation of power in the propinquity of demand site.

Stand-alone systems produce power independently of the utility grid; hence, they are said to stand-alone. These are more suitable for remotest locations where the grid cannot penetrate and there is no other source of energy. These systems are not connected to the 
utility grid as a result they need batteries for storage of electricity produced during off-peak demand periods, leading to extra battery and storage costs. It is prudent that neither a standalone solar nor a wind energy system can provide a continuous supply of energy due to seasonal and periodical variations. Therefore, in order to satisfy the continuous load demand in remote locations, hybrid energy systems are implemented on combined solar and wind energy conversion unit with battery storage.

In this paper a control scheme is proposed for the BESS to maintain the balance between supply and demand in the scenarios of variable renewable resources power and variable load. In section I there is some discussion have been carried regarding advantages of solar-wind based power system which is not connected to grid. In section II modelling of the solar-wind based hybrid system is carried out. Section III describes the control scheme employed for the BESS. The results and discussion is carried out in section IV and the paper is concluded in the section $\mathrm{V}$.

\section{Modelling the components of Solar-Wind based Power System}

Due to fluctuation and variability in power produced from renewable sources like wind and solar, considering a form of energy storage to backup power fluctuation is very important. Therefore, short-term and/or long-term energy storage, such as batteries, SMES or super-capacitors and/or hydrogen storage tanks, must be used to achieve a reliable and safe operation and to maintain the required power supply during power fluctuation, interruption, failure or high power peak conditions. To achieve this, system components should be selected carefully and the control system must ensure that hybrid power system components are well managed and monitored properly. This chapter will cover a brief description of the important hybrid system components used in this work:
(1) PV System.
(2) Wind energy conversion system.
(3) Battery Energy Storage System.

\section{A. PV System}

The equivalent electrical circuit of a PV cell is given in Figure 1. It is a one diode model which is also known as the 5 parameter circuit. The cell can be modeled by other equivalent circuits as well; such as 7 parameters but the one diode model is the most commonly used circuit in the literature and the solution of the circuit is not as complicated as is the case in other models. The parameters in the circuit are; $\mathrm{I}_{\mathrm{D}}, \mathrm{I}_{\mathrm{L}}, \mathrm{I}_{\mathrm{SH}}, \mathrm{R}_{\mathrm{SH}}, \mathrm{R}_{\mathrm{S}}, \mathrm{I}$ and $\mathrm{V}$.

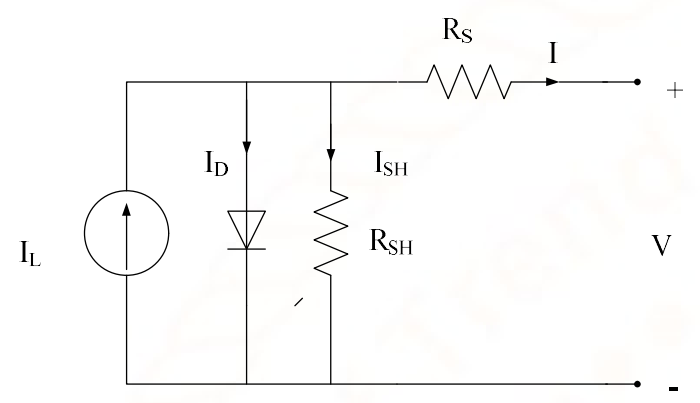

Figure 1 Equivalent circuit of a solar cell.

From the circuit;

$I=I_{P H}-I_{D}-I_{S H}$

$\mathrm{I}_{\mathrm{PH}}$ (photo-generated current) is also called as $\mathrm{I}_{\mathrm{L}}$ (light current) which refers to direct current generated by photovoltaic effect. Whereas I is the output current of the cell.

From Shockley's diode equation;

$I_{D}=I_{0}\left[\exp \left(\frac{V+I R_{S}}{n V_{t}}\right)-1\right]$

Where;

$V_{t}=\frac{k T}{q}$

By Ohm's Law

$I_{S H}=\frac{V+I R_{S}}{R_{S H}}$

Equation (5) is the general solar cell characteristic equation which is available in the literature [4]. From the characteristic equation, it is possible to evaluate cell current for a given cell temperature and voltage. However, analytic solution of the equation is not possible and numerical methods will be used to solve the equation. The parameters that need to be defined 
before solving Equation (5) are After substituting equations (2), (3), and (4) into equation (1), the equation takes the form of;

$I_{D}=I_{P H}-I_{0}\left[\exp \left(\frac{V+I R_{S}}{A V_{t}}\right)-1\right]-\frac{V+I R_{S}}{R_{S H}}$

$\mathrm{R}_{\mathrm{SH}}, \mathrm{R}_{\mathrm{S}}, \mathrm{A}, \mathrm{I}_{\mathrm{PH}}$ and $\mathrm{I}_{0}$. These parameters are specific to every different commercial PV array and will be calculated from the product data sheet values tested at the Standard Test Conditions (STC) or Reference Point which is $1 \mathrm{~kW} / \mathrm{m} 2$ solar irradiation and $25^{\circ} \mathrm{C}$ cell temperature. Knowing these parameters, solar radiation data and the cell temperature will allow us to calculate the electricity generation of the solar cell.

\section{B. Wind Turbine Energy Conversion System}

Wind generation is classified into two major wind power generating units i.e. fixed speed generation and variable speed generation (VSG). The fixed speed generators operate at a fixed rotor speed to obtain maximum efficiency. Deviation from the pre determined speed causes reduction in efficiency. VSG inherits a wide range of operating speeds for the rotor to match up with prevailing wind for better efficiency. VSG has maximum power tracking capability that extracts maximum available power out of the wind at different wind speeds thereby resulting in more efficient operation. Also VSG reduces mechanical stresses on the turbine thus increasing the lifetime of the turbine. Thus VSG's are more commonly installed. The wind turbine dynamics have been widely studied. In both forms of wind power generation the power extraction principle remains the same. The amount of power generated by the turbine can be associated with the torque generated by the wind. The model base equation represents the mechanical power, Pmech, harnessed from the wind, Equation 6.

$P a=\frac{1}{2} \rho \pi r^{2} \mathrm{C}_{\mathrm{p}}(\lambda, \beta) \mathrm{V}_{\mathrm{w}}^{3}$

$\lambda=\frac{R \Omega}{V_{w}}$

Here $P_{a}$ is the wind power converted in to electrical power, $\pi r^{2}$ is the rotor swept area, $\mathrm{C}_{\mathrm{p}}$ is the power co- efficient, $\lambda$ is the tip speed ratio, $\beta$ is the pitch angle and $V_{w}$ is the wind speed. The tip speed ratio is defined as the ratio between the blade tip speed and the wind speed $V_{w}$

Where $\Omega$ is the turbine rotor speed and $\mathrm{R}$ is the radius of the wind turbine blade.

\section{Battery Energy Storage System (BESS)}

An electrical battery is chosen as energy storage system for this study. The complete BESS comprises: a battery, filter and IGBT converter

Various types of batteries can be used in power systems. Four of the most common battery types are: Lead Acid, Nickel Cadmium, Nickel Metal Hydride, Lithium-Ion. Although Nickel Metal Hydride (Ni$\mathrm{MH}$ ) batteries present a higher cost than other types, it has been chosen for its environmental-friendly aspect [5].

The battery mathematical model is based on reference [6]. The model in [6] has been widely used in power system studies. It has also been implemented in the SIMULINK' Sim Power Systems library. The model is implemented through a controllable voltage source regulated by Equation 7 and Equation 8 .

$E=E_{0}-K\left(\frac{Q}{Q-\int i_{\text {batt }} d t}\right)+A^{-B \int i_{\text {batt }} d t}$

$V_{\text {batt }}=E_{\text {batt }}-i_{\text {batt }} R_{\text {batt }}$

where, $E$ is the internal voltage, $V_{\text {batt }}$ is terminal voltage and $i_{\text {batt }}$ is the current. The battery parameters, $\mathrm{A}, \mathrm{B}, \mathrm{K}, \mathrm{R}, \mathrm{Q}$ and $\mathrm{E}_{0}$, are defined in Table 1 .

Table-I Parameters of BESS

\begin{tabular}{|c|c|}
\hline Parameter & Definition \\
\hline $\mathbf{A}$ & Exponential zone amplitude (V) \\
\hline B & $\begin{array}{l}\text { Exponential zone time constant inverse } \\
\left(\mathrm{Ah}^{-1}\right)\end{array}$ \\
\hline $\mathbf{K}$ & Polarization voltage (V) \\
\hline $\mathbf{R}_{\text {batt }}$ & $\mathrm{R}_{\text {batt }} \quad$ Battery internal resistance $(\Omega)$ \\
\hline $\mathbf{E}_{0}$ & $\mathrm{E}_{0} \quad$ Battery constant voltage $(\mathrm{V})$ \\
\hline $\mathbf{Q}$ & Q $\quad$ Capacity $(\mathrm{Ah})$ \\
\hline
\end{tabular}




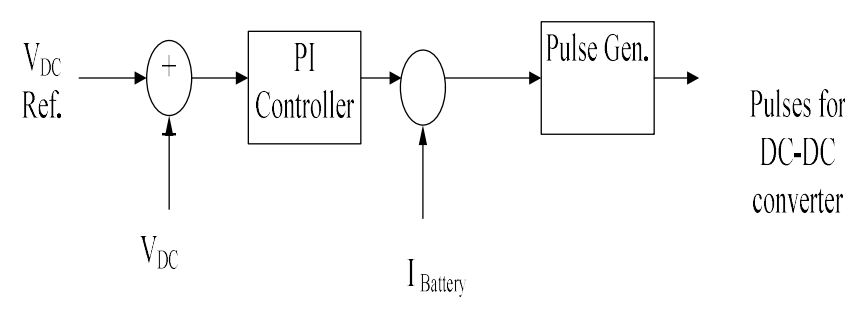

Fig. 2. Control scheme for DC-DC conversion

\section{Control Scheme}

The hybrid power system is using PV, Wind turbine and battery as the power sources or sinks at different interval of time, so there are needs to share the power within these sources/sinks effectively. PV system output power is weather dependent, sometime PV system produces more power than the requirement and this excess power should be stored in the BESS which can be later used in with demand is more than the requirement. To maintain the power according to the load classical PI controller is used for power management among the different parts of the HPS. A central controller is used for fuel cell system, BESS and PV system for DC-DC conversion as well as for $\mathrm{DC}-\mathrm{AC}$ conversion shown in fig..

As the output of PV system, BESS and WECS system is $\mathrm{DC}$, so it has to be converted in to suitable $\mathrm{AC}$ form with AC converter. First of all the three phase AC voltage and current are measured and converted into RMS values and compared with the reference voltage i.e. 1 pu. The error is then goes to the PI controller and again this is converted back in to three phase quantities. This signal is fed to the pulse generator which produces pulses for the inverter circuit.

\section{Results and Discussion}

The solar-wind based power system is modeled and implemented in MATLAB/Simulink. The details of the modelling are given in section III. In this section the proposed system is subjected to variable solar irradiance as well as variable wind speed. In addition to this variable load is connected to the system. These will lead to the continuous difference between supply and demand. So BESS overcome this problem and the results are shown in the following figures.

For analyzing the validity of the solar-wind based power system is subjected to different levels of solar irradiance. For the time interval 0-2 second the solar irradiance level is $1000 \mathrm{~W} / \mathrm{m}^{2}$. For secon time interval between 2-6 second the solar irradiance level is reduced to $800 \mathrm{~W} / \mathrm{m}^{2}$ shown in the figure 3 . As the irradiance level is decreased the output current and the output power of the PV system also decreased. For the simplicity only one time change in the solar irradiance is done otherwise the other waveforms will be overcrowded and cannot be clearly visible.

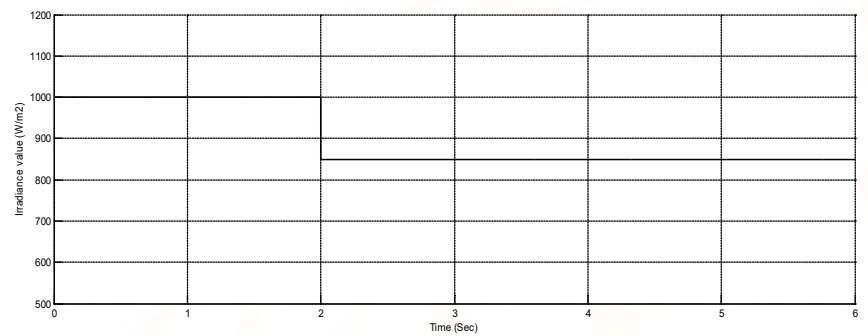

Fig. 3.Solar Irradiance level

Figure 4 is showing solar irradiance versus MPPT voltage waveform. From this it is clearly understood that the irradiance level decides the MPPT voltage. As the irradiance level decreased the MPPT voltage also reduces.

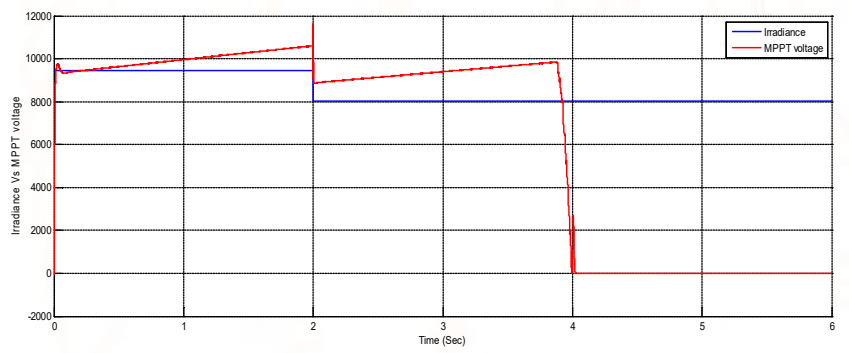

Fig. 5.Solar Irradiance level Vs PV MPPT voltage

For compensating the shortfall in the PV system power BESS reacts according to the requirement.

For these purpose BESS controllers gives the command to the converter circuit and further it supply power to the demand. If the BESS state of charge (SOC) less than the minimum value then BESS does not comes in to action. In the figure 6 BESS current waveform is shown. From the figure it is found that when the PV system output decreases, BESS power increased to compensate this shortfall.

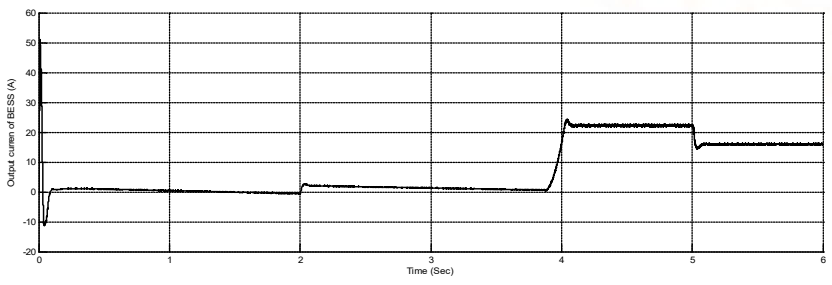

Fig. 6 Output current of the BESS. 
For the second case, there is change in load is made at the time $4 \mathrm{sec}$. initially the system is connected to the $10 \mathrm{KW}$ resistive load. There is a step increase of additional $3 \mathrm{KW}$ load is made at time $4 \mathrm{sec}$. this additional load I s removed at time $5 \mathrm{sec}$. Figure 7 shows the waveform of the power drawn by the load.

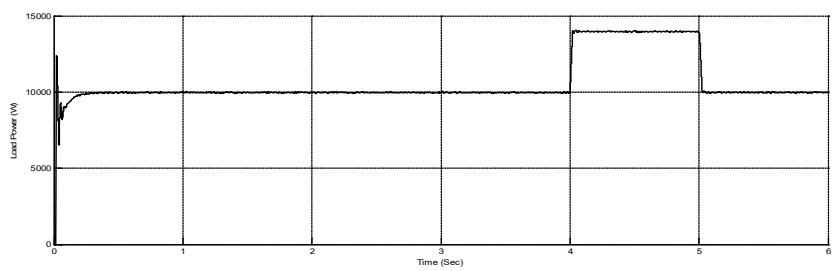

Fig. 7.Power drawn by the load.

When the load is increased the HPS system start supplying more current to meet the requirement. In the previous case it is described that shortfall in the PV system is compensated by the BESS. Here also when the load increases, this additional requirement is fulfilled by the BESS if the PV system and fuel cell system both are not capable of meeting the demand.

\section{Conclusions}

In this paper, off-grid power systems are modeled and system parameters are analyzed using a MATLAB/Simulink. The paper is focused on the effects of system components and on the total performance of the system. The photovoltaic Panels, BESS and the fuel cell system are modeled individually using MATLAB 7.12.0. The system is subjected with the two types of perturbances, i.e. change in load, change in solar irradiance level and wind speed.

The power management technique based upon classical PI controller is used for sharing the power according to the load and environmental conditions. The study shows how energy stored in the can be used as a key system performance indicator, provided that no system constraints are violated. The performance of the system can be significantly affected by the small variations made on the system elements.

BESS is the only energy storage for a Stand-Alone Power System. The system is based on electricity-tochemical and chemical-to electricity conversion which is an inefficient way of handling the extra energy.

\section{References}

[1] Kazmerski LL. "Photovoltaics: a review of cell and module technologies". Renew Sustain Energy Rev 1997;1(1-2):71-170.

[2] Asif M, Muneer T. "Energy supply, its demand and security issues for developed and emerging economies". Renew Sustain Energy Rev 2007;11(7):1388-413.

[3] Deepak P, Balachandra P, Ravindranath NH. "Grid-connected versus standalone energy systems for decentralized power-a review of literature". Renew Sustain Energy Rev, in press.

[4] D. Sera, R. Teodorescu, P. Rodriguez, "PV panel model based on datasheet values", Industrial Electronics, 2007. ISIE 2007. IEEE International Symposium, pp. 2392-2396, 2007.

[5] R. Sebastián and R. P. Alzola, "Effective active power control of a high penetration wind diesel system with a $\mathrm{Ni}-\mathrm{Cd}$ battery energy storage," Renewable Energy, vol. 35, 2010, pp. 952-965.

[6] R. Sebastián, "Reverse power management in a wind diesel system with a battery energy storage," International Journal of Electrical Power \& Energy Systems, vol. 44, no. 1, 2012, pp. 160-167. 